\title{
Sequential Morphological Changes in the CNV Net after Intravitreal Anti-VEGF Evaluated with OCT Angiography
}

\author{
João Pedro Marques ${ }^{a, b}$ José Filipe Costa ${ }^{a}$ b Marco Marques ${ }^{a, b}$ \\ Maria Luz Cachulo $^{a-c}$ João Figueira ${ }^{a-c}$ Rufino Silva ${ }^{a-c}$ \\ ${ }^{a}$ Department of Ophthalmology, Centro Hospitalar e Universitário de Coimbra (CHUC), ${ }^{b}$ Association for Innovation \\ and Biomedical Research on Light and Image (AIBILI) and 'Faculty of Medicine, University of Coimbra (FMUC), \\ Coimbra, Portugal
}

\section{Key Words}

Age-related macular degeneration - Antivascular endothelial growth factor - Choroidal neovascularization . Imaging - Optical coherence tomography angiography . Image analysis

\section{Abstract}

Purpose: To assess and describe sequential morphological changes in the choroidal neovascularization (CNV) net using optical coherence tomography angiography (OCTA) in patients undergoing treatment with intravitreal antivascular endothelial growth factor (VEGF). Methods: Prospective cohort study. OCTA was performed sequentially: before (t0), $1 \mathrm{~h}(\mathrm{t} 1), 1$ week (t2) and 1 month after the injection (t3), using Avanti RTVue XR equipped with the AngioVue ${ }^{\circledR}$ software (Optovue, Calif., USA). All images were classified by two independent graders. Results: Ten eyes of 10 patients, with a mean age of $72.4 \pm 10.5$ years, were included. CNV morphology was described as tree-like in 5 eyes, glomerular in 1 and fragmented in 4. A fibrovascular capsule surrounding the CNV net was found in 4 eyes and a feeder trunk was noticed in 6 . No changes were observed at $t 1$. Loss of peripheral capillaries, vessel fragmentation and decreased vessel density were evident in 8 eyes at $\mathrm{t} 2$. The CNV capillary density and the peripheral anastomosis increased in all of these at $\mathrm{t} 3$. Two eyes remained unchanged through the whole length of follow-up. Conclusions: Significant changes in the CNV net can be observable in OCTA at least 1 week after intravitreal anti-VEGF. The safety of frequent examinations may provide a method of gauging treatment effects.

(c) 2016 S. Karger AG, Basel

\section{Introduction}

Age-related macular degeneration (AMD) is the leading cause of irreversible, severe vision loss in developed countries among people aged $\geq 55$ years [1]. In neovascular AMD, the presence of abnormal blood vessels arising from the choroid - choroidal neovascularization $(\mathrm{CNV})$ - can be found between Bruch's membrane and the retinal pigmented epithelium (type 1) or in the subretinal space (type 2). The angiogenesis associated with the CNV lesions leads to bleeding, exudation and ultimately to the formation of a fibrovascular scar, resulting in severe photoreceptor damage and vision loss [2]. Early diagnosis is crucial for initiating and guiding treatment, which nowadays relies on repeated intravitreal injections of monoclonal antibodies to the vascular endothelial growth factor

\section{KARGER}

E-Mail karger@karger.com

www.karger.com/ore
C 2016 S. Karger AG, Basel

0030-3747/16/0553-0145\$39.50/0
João Pedro Marques, MD, MSc

Department of Ophthalmology, Centro Hospitalar e Universitário de Coimbra Praceta Prof. Mota Pinto

PT-3049-075 Coimbra (Portugal)

E-Mail marquesjoaopedro@ gmail.com 
(VEGF). Anti-VEGF drugs blunt the progression of the disease process by halting the germination of new vessels and decreasing VEGF-mediated vascular leakage, hence reducing the risk of progressive and enduring visual loss. Ancillary diagnostic tests like fluorescein angiography (FA), indocyanine green angiography (ICGA) and spectral domain optical coherence tomography (SD-OCT) have led to a better understanding of the pathophysiological features of several retinal diseases, including AMD [3]. FA remains the gold standard for the diagnosis and classification of AMD-related CNV, whereas ICGA is used to image subretinal pigmented epithelium components of the CNV, as it offers better visualization of the deep vessels due to excitation and resultant fluorescence in the near-infrared region [4]. Both FA and ICGA are invasive imaging techniques that require intravenous injection of a dye - fluorescein or indocyanine green, respectively. Although generally safe, side effects like nausea, vomiting or even severe allergic reactions may develop in a minority of patients, thus limiting its repeated use $[5,6]$. The advent of OCT revolutionized retinal imaging by providing a fast, simple and noninvasive method to assess retinal structure at a microscopic level $[7,8]$. The high resolution of SD-OCT allows visualization of some morphological features of the fibrovascular complex and the exudative consequences of fluid accumulation in the retina. However, even the most advanced structural OCTs do not provide an adequate visualization of the choriocapillaries.

OCT angiography (OCTA) is a revolutionary imaging technique that allows noninvasive, 3-dimensional visualization of the retinal and choroidal vasculature via motion contrast imaging $[9,10]$. OCTA detects endoluminal flow by mapping erythrocyte movement over time and comparing sequential OCT B scans at a given cross-section [9]. By using the en face OCT technology, layer segmentation is automatically generated to identify areas of interest, such as the superficial and deep retinal vascular plexuses or the choriocapillaries $[11,12]$. In order to minimize unavoidable saccadic artifacts and the signal-tonoise ratio of flow detection, amplitude-based algorithms, calculating differences in intensity between structures, were developed $[13,14]$. Motion correction is achieved by merging two orthogonally captured imaging volumes. The split-spectrum amplitude-decorrelation angiography algorithm is a patented primary technology described by Jia et al. [13] that improves both signal-to-noise ratio for flow detection and connectivity of microvascular network, by splitting the spectrum of two original repeat OCT frames. The incorporation of these technologies in OCTA further enhanced the quality of the vascular im- ages, thus enabling the in vivo acquisition of high-speed, dyeless, microvascular angiograms, representing a true extension of capabilities from SD-OCT $[10,15]$.

While still in a germinal stage, studies on the clinical applications of OCTA are beginning to materialize, namely in the field of exudative AMD [4, 9, 10, 16-18]. OCTA has been shown to allow a noninvasive evaluation of the CNV net [19-21], with 50 and $91 \%$ reported sensitivity and specificity for CNV detection, respectively [9]. Its inherent advantages appear to be the ability to optically dissect and visualize flow in different layers of the retina, the high obtainable resolution and the freedom and safety of frequent examinations [22]. Anecdotal case reports $[17,20,23]$ have shown that changes in the CNV net can be expected to occur after treatment with antiVEGF drugs. Quantitative measurements of the CNV flow area and flow index reported by Huang et al. [20] showed a rapid shutdown of flow over the initial 2 weeks, followed by reappearance of the CNV channel by the fourth week and fluid reaccumulation at 6 weeks. In accordance with this, Lumbroso et al. [19] described a pattern of cyclic variation in the CNV net after each antiVEGF injection, starting as soon as $24 \mathrm{~h}$ after treatment. A comprehensive assessment of the CNV net changes that each patient undergoes during treatment may lead to better monitoring of treatment response and ultimately to the development of customized treatment regimens. Using a fixed schedule of OCTA examinations (before, $1 \mathrm{~h}$ after, 1 week after and 1 month after intravitreal antiVEGF), this study was designed to (1) assess and describe sequential morphological changes in the $\mathrm{CNV}$ net in a cohort of exudative AMD patients undergoing treatment with intravitreal injections of anti-VEGF and (2) evaluate whether the reported changes in the CNV net can be seen as soon as $1 \mathrm{~h}$ after treatment.

\section{Methods}

Prospective cohort study. The study followed the tenets of the Declaration of Helsinki for biomedical research and was approved by the local Ethics Committee. Informed consent was obtained for every included subject.

Patients undergoing intravitreal injections of anti-VEGF compounds for AMD-related CNV were included in the study. Eligibility criteria were: (1) either race or sex; (2) confirmed diagnosis of AMD-related $\mathrm{CNV}$ with ancillary multimodal retinal imaging, i.e. color fundus photography, FA, ICGA and SD-OCT; (3) ability to attend regular follow-up visits; (4) ability to maintain accurate target fixation, and (5) no significant media opacities likely to jeopardize image acquisition or interpretation. Patients with a visual acuity of $20 / 100$ or less and those with a signal strength of 55 or less were not included in this study.
Marques/Costa/Marques/Cachulo/ Figueira/Silva 
Optical Coherence Tomography Angiography

OCTA was performed with the $70-\mathrm{kHz}$ Avanti RTVue XR equipped with the AngioVue software (Optovue Inc., Fremont, Calif., USA), with a light source centered at $840 \mathrm{~nm}$, a bandwidth of $45 \mathrm{~nm}$, and an A scan rate of 70,000 scans/s. The macular angiography scans covered a $3 \times 3 \mathrm{~mm}$ area, each macular cube consisting of 304 clusters of 2 repeated B scans containing 304 A scans each. Motion correction and the split-spectrum amplitude-decorrelation angiography algorithm were employed to minimize unavoidable saccadic artifacts and improve the signal-to-noise ratio, respectively. OCTA was performed sequentially in the $\mathrm{CNV}$ group: before the intravitreal injection ( $\mathrm{t} 0), 1 \mathrm{~h}(\mathrm{t} 1), 1$ week ( 2 ) and 1 month after the injection ( $\mathrm{t} 3$ ). Automated segmentation was used to visualize neovascular tissue in the plane above Bruch's membrane. However, when automated techniques failed, the area of segmentation was manually adjusted until the tissue of interest was visualized. The best images that showed neovascular tissue were chosen for analysis.

\section{Image Analysis}

All images were classified by two independent graders (J.P.M. and J.C.). For the certification process, the graders had to successfully identify the CNV net and its morphology in a set of 20 OCTA images of patients attending the AMD clinic of our center. In the baseline scans ( $\mathrm{t} 0$ ), the $\mathrm{CNV}$ net morphology was categorized into tree-like, glomerular or fragmented, as previously described by Lumbroso et al. [11]. The presence of a fibrovascular capsule and feeder trunk were assessed. In the sequential analysis of the OCTA scans, the status of the CNV net and surrounding choriocapillaris were thoroughly evaluated, specifically searching for loss of peripheral capillaries, vessel pruning or fragmentation and decreased vascular density.

\section{Results}

Demographic and clinical characteristics of the included patients are shown in table 1 . Ten eyes of 10 patients with neovascular AMD and a mean age of $72.4 \pm$ 10.5 years, were included in this study. All patients completed 1 month of follow-up and attended all the scheduled visits ( $\mathrm{t} 0, \mathrm{t} 1, \mathrm{t} 2$ and $\mathrm{t} 3$ ). Three patients were treatment naive, while all the others had already received at least 1 intravitreal injection of ranibizumab. The CNV net was discernible in the OCTA scan of every patient. Its location was compared with color fundus photography, FA and ICGA. In all cases, OCTA provided a more distinctive pattern of the vascular network, not obscured by leakage or subretinal hemorrhage (fig. 1c, d). The CNV net originated from regions of severe choriocapillaris alteration. In the baseline scans ( $\mathrm{t} 0$ ), the $\mathrm{CNV}$ morphology was described as tree-like in 5 eyes, glomerular in 1 and fragmented in 4 (fig. 2a, b, c). The presence of a fibrovascular capsule surrounding the CNV net was found in 4 eyes, and a central feeder trunk was noticed in 6 (fig. 2a, c, d).
Table 1. Clinical and demographic data from the study population

\begin{tabular}{llllllll}
\hline $\begin{array}{l}\text { Case } \\
\text { years } \\
\text { years }\end{array}$ & Sex Eye & $\begin{array}{l}\text { Type of } \\
\text { CNV }\end{array}$ & BCVA & $\begin{array}{l}\text { Number of previ- } \\
\text { ous injections }\end{array}$ & $\begin{array}{l}\text { Current } \\
\text { anti-VEGF } \\
\text { compound }\end{array}$ \\
\hline 1 & 89 & F & L & Type 1 & $20 / 80$ & 3 Ranibizumab & Ranibizumab \\
2 & 79 & F & R & Type 1 & $20 / 80$ & 11 Ranibizumab & Ranibizumab \\
3 & 60 & F & R & Type 1 & $20 / 40$ & 5 Ranibizumab & Ranibizumab \\
4 & 70 & F & R & Type 1 & $20 / 50$ & 2 Ranibizumab & Ranibizumab \\
5 & 67 & M & L & Type 1 & $20 / 25$ & 0 & Aflibercept \\
6 & 56 & F & L & Type 1 & $20 / 40$ & 0 & Ranibizumab \\
7 & 82 & F & L & Type 1 & $20 / 80$ & 18 Ranibizumab & Ranibizumab \\
8 & 80 & M & R & Type 2 & $20 / 80$ & 3 Ranibizumab & Ranibizumab \\
9 & 76 & F & R & Type 1 & $20 / 60$ & 1 Ranibizumab & Ranibizumab \\
10 & 65 & F & L & Type 2 & $20 / 30$ & 0 & Aflibercept \\
\hline
\end{tabular}

BCVA = Best-corrected visual acuity; $\mathrm{L}=$ left; $\mathrm{R}$ = right.

One hour (t1) after the intravitreal injection, no changes in the CNV net were observed in any of the included subjects. Loss of peripheral capillaries, vessel pruning or fragmentation and decreased vessel density were evident in 8 eyes at $\mathrm{t} 2$ ( 1 week after the injection), even though the central, larger vessels remained unchanged. The $\mathrm{CNV}$ capillary density and the peripheral anastomosis increased in all of these cases from t 2 to $\mathrm{t} 3$ (fig. 1f, g, h, i, fig. 3). No discernible changes in the CNV net were found through the whole length of follow-up in 2 eyes (cases 2 and 7).

\section{Discussion}

Previous studies have demonstrated that OCTA allows accurate imaging of AMD-related type 1 and type $2 \mathrm{CNV}$ $[9,10,16,18,21]$. Correspondingly, in this study the CNV net was detectable in the baseline OCTA scan of every included patient, allowing a comprehensive visualization of the morphology and microvascular details of the CNV net, not obscured by leakage or subretinal hemorrhage. Furthermore, sequential changes after anti-VEGF treatment were identified in $80 \%$ of our study population, which was in agreement with the notion that following treatment with anti-VEGF, the level of free VEGF drops precipitously, and newly growing vascular sprouts regress [4]. Even though several authors have reported longitudinal changes in the neovascular network after treatment, most of these are anecdotal case reports [17, 20,23] or small case series [24] with varying OCTA evaluations over time. Albeit important, case reports have significant limitations, namely the fact that their observations can- 

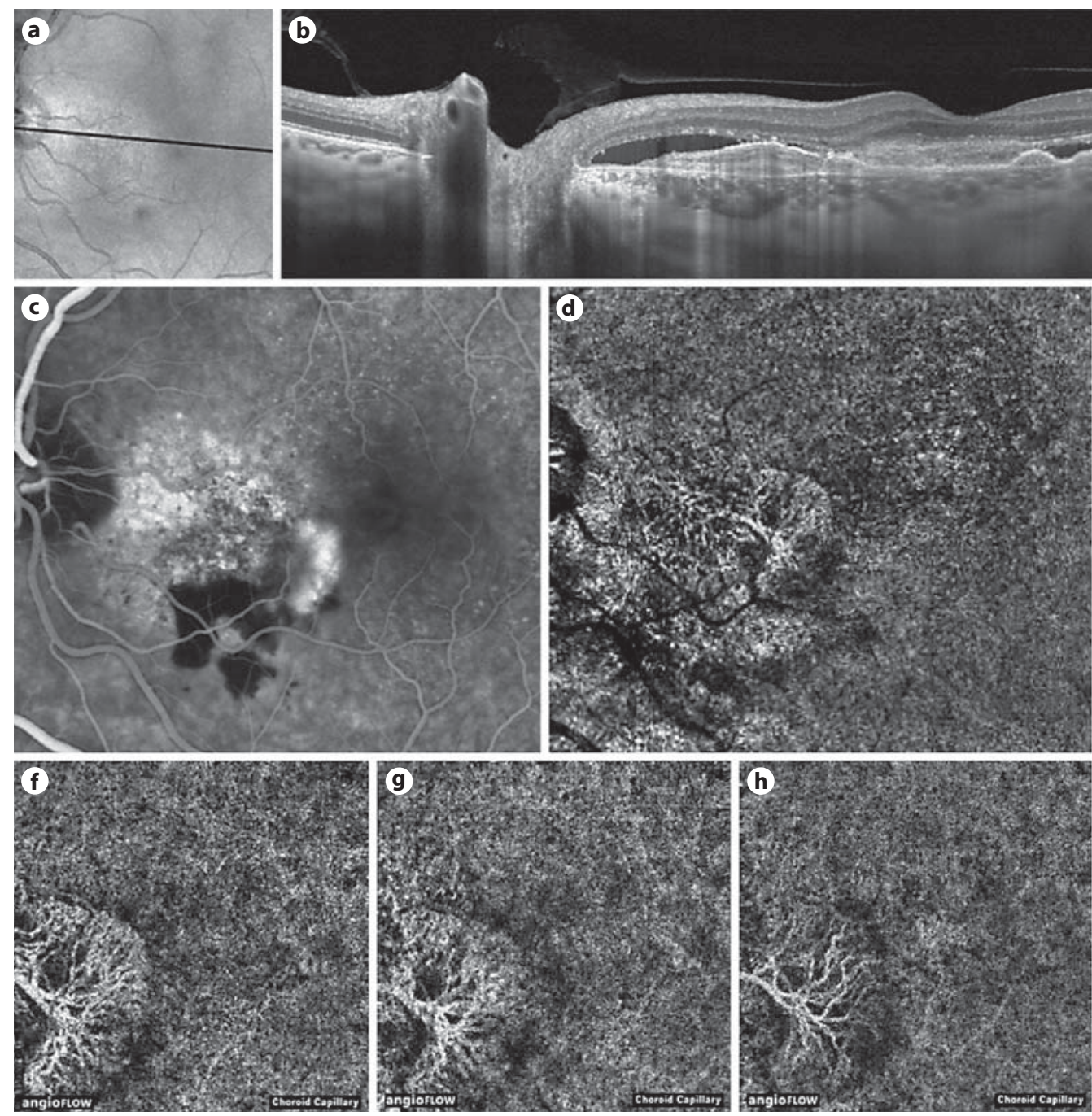

Fig. 1. Multimodal retinal imaging of a 67-year-old treatment-naive male (case 5). a Infrared photography. b A horizontal scan of enhanced-depth imaging SD-OCT at the corresponding black line in a showing a type 1 parafoveal CNV lesion accompanied by subretinal fluid and a subretinal hemorrhage. $c$ In the FA, visualization of the CNV net is obscured by leakage. d An $8 \times 8 \mathrm{~mm}$ OCTA scan shows a comprehensive glomerular-like CNV morphology, represented as a sketch in e. Sequential $3 \times 3 \mathrm{~mm}$ OCTA scans are depicted in the bottom set of images: before $(\mathrm{t} 0 ; \mathbf{f})$ the intravitreal injection of aflibercept the glomerular-like CNV net with a central

not be extrapolated to a clinical practice scenario. Sequential OCTA imaging in fixed intervals enables us to shadow the behavior of the CNV net after treatment, closely tracking the timings of vascular network remodeling. This was demonstrated by Lumbroso et al. [19] in a small cohort of 5 treatment-naive type $2 \mathrm{CNV}$ patients. The authors reported changes in the $\mathrm{CNV}$ net starting as
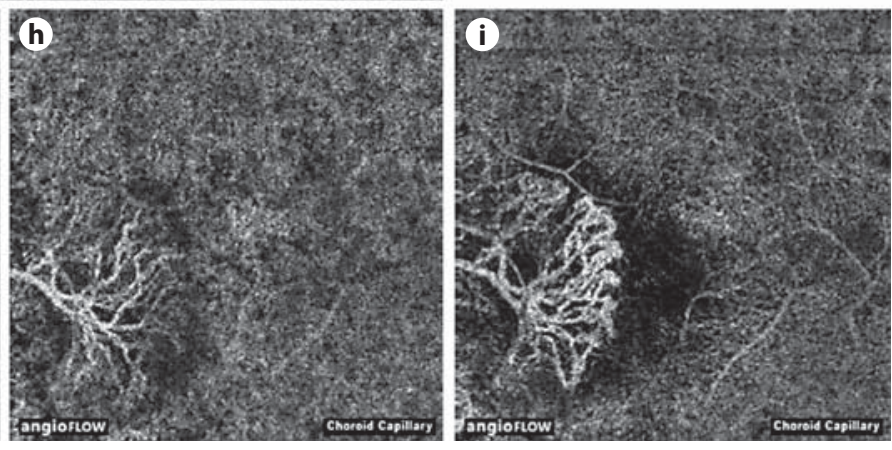

feeder trunk and peripheral anastomosis is clearly observed; $1 \mathrm{~h}$ after the injection $(\mathrm{t} 1 ; \mathbf{g})$ there is no significant change in the CNV net; however, 1 week after the injection $(t 2 ; \mathbf{h})$ marked regression of the peripheral anastomosis and substantial capillary dropout can be seen, along with decreased new vessel density. The feeder trunk and some other central vessels are still visible. i Note recanalization of the peripheral anastomosis, resumption of capillary sprouting and increased new vessel density 1 month after the intravitreal injection $(\mathrm{t} 3)$. soon as $24 \mathrm{~h}$ after the injection and becoming progressively more profuse up to $12-18$ days after treatment. New vessel regrowth was noted 28-35 days after injection. In our study protocol we decided to evaluate whether these changes could be observable even earlier, i.e. $1 \mathrm{~h}$ after the intravitreal anti-VEGF injection. To our knowledge this was the first study to use fixed OCTA imaging 
Fig. 2. a A typical tree-like CNV morphology with a central feeder trunk (white arrow) and branching ramifications (case 9). b A fragmented CNV net morphology that did not change during the whole length of follow-up, in an 82-year-old female who had already undergone 18 ranibizumab injections (case 7). c A typical glomerularlike pattern with a central feeder trunk (white arrow) and peripheral capillary sprouting (case 5). d Note a fibrovascular capsule surrounding the CNV net (dashed line).
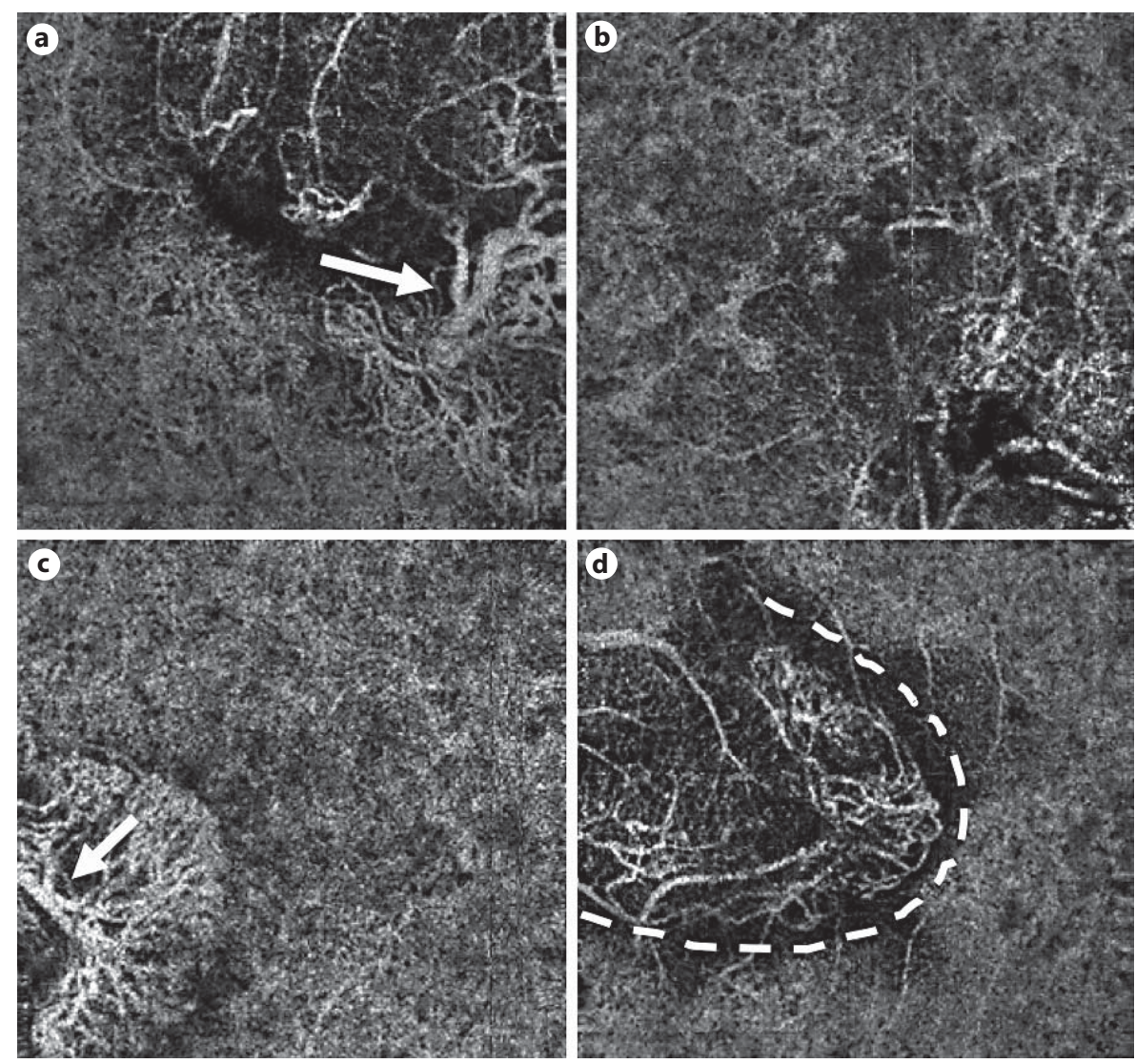
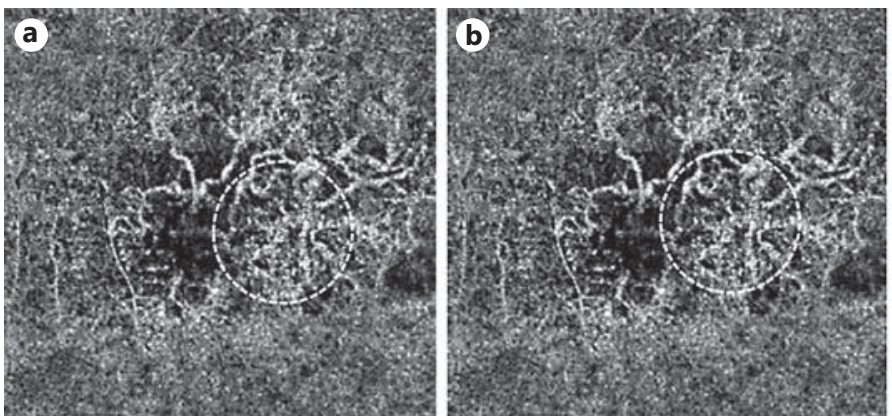

Fig. 3. Sequential OCTA scans of a 60-year-old female with a history of 5 previous intravitreal injections of ranibizumab (case 3). a Baseline scan ( $\mathrm{t} 0$ ) showing a tree-like CNV morphology. b One hour ( $\mathrm{t} 1$ ) after the intravitreal injection of ranibizumab, no apparent changes in the CNV net could be observed. c One week after
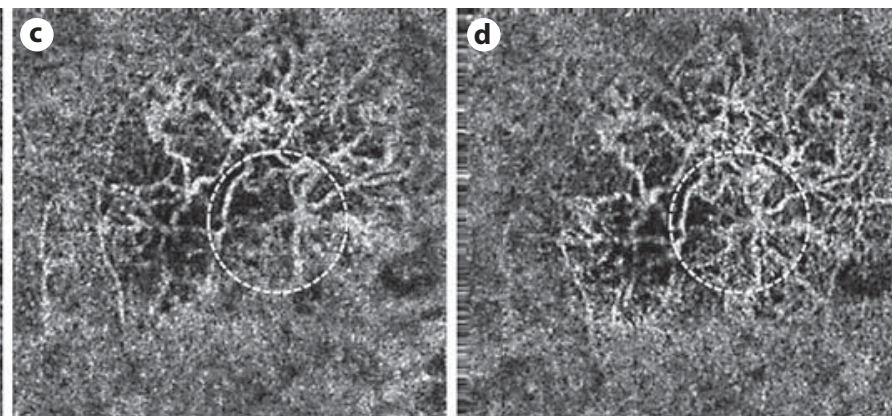

the injection, there is modest capillary dropout (center of the dashed white circle) with regression of some peripheral anastomosis. d One month after the injection, central capillary density increases, and the CNV net looks similar to the baseline scan.

served (fig. 1h, 3c), even though the central, larger vessels remained unchanged. The vulnerability of the branching peripheral capillaries is thought to occur due to the lack of pericytes shielding the vascular endothelial cells [25]. On the other hand, the adequate pericyte coverage of the feeder trunk renders it resistant to anti-VEGF therapy 
alone, as the pericytes supply VEGF locally to their associated vascular endothelial cells [4]. Following the collapse of the peripheral newly formed capillaries, the vascular resistance for the entire vascular circuit rises, hence increasing the flow through the persisting vessels [4]. This is a stimulus for arteriogenesis, a phenomenon that leads to dilation of preexisting vessels by active proliferation and remodeling of the vessel wall [26]. Unlike angiogenesis (sprouting of new capillaries), arteriogenesis is not VEGF dependent. Spaide [4] has recently highlighted that as the levels of anti-VEGF wane and unbound VEGF rises, resumption of capillary sprouting inevitably follows. This was later demonstrated by Lumbroso et al. [19] and was also observed in our study, where all cases that showed response to the anti-VEGF at t 2 eventually increased capillary density and the peripheral anastomosis from $\mathrm{t} 2$ to t3 (fig. 1i, 3d). In the light of the current knowledge, the capillaries grow out of the formerly pruned larger branches that expand in size due to arteriogenesis [26]. Repeated anti-VEGF treatment trims back the newly growing vessels and a vicious cycle ensues [19]. Thus, the new vessel ingrowth caused by anti-VEGF compounds is nothing but periodic pruning of newly growing vessels (angiogenesis) in a setting of an unceasing stimulus for dilation (arteriogenesis). Even though this approach is known to blunt the progression of the disease process by halting the sprouting of new capillaries and reducing VEGF-mediated vascular leakage, treating one feature of neovascularization may not necessarily affect others [4]. Albeit good, the current management of neovascular AMD is far from ideal and keeps the door open for emerging therapeutic options [27]. Platelet-derived growth factor stimulates angiogenesis, as well as pericyte recruitment and maturation [28]. Therefore, inhibition of platelet-derived growth factor may increase endothelial cell sensitivity to antiVEGF agents. A phase III clinical trial with E10030 (Fovista $^{\circledR}$, Ophthotech Corporation, Princeton, N.J., USA), an anti-platelet-derived growth factor, is currently ongoing to compare its efficacy when used concomitantly with ranibizumab versus ranibizumab monotherapy in subjects with subfoveal CNV (NCT01940900).

In 2 of our patients, no significant changes were found during the whole length of follow-up. Interestingly, these were the 2 cases with more previous intravitreal injections of anti-VEGF (11 and 18), which inevitably raises the question of tachyphylaxis. It would be interesting to appreciate whether a switch in the anti-VEGF agent would lead to any kind of vessel contraction in these settings. Unfortunately this was not attempted in the current study.
By determining the exact moment when the antiVEGF drug wanes in a certain patient we could potentially tailor individual regimens instead of using fixed monthly injections. Measuring the aqueous or vitreous levels of VEGF are invasive and unfeasible procedures to use in clinical practice [29-31]. With SD-OCT we can assess the presence of subretinal fluid and pigment epithelial detachments but we cannot accurately depict the CNV net. However, we may be able to use OCTA to provide customized treatment regimens depending on the $\mathrm{CNV}$ type and its response to intravitreal anti-VEGF, thus changing the current treatment regimens for exudative AMD. Future studies are needed to demonstrate this hypothesis.

Limitations of this study include the restricted sample size, making it necessary to validate our findings and hypothesis in further prospective reports involving a larger number of patients. Also, a quantitative analysis of the morphological changes was not performed in this study. Our results are purely descriptive, and a future evaluation of the clinical impact of its findings is warranted. The biggest strength of this study relies on its longitudinal design and reproducible methodology.

In conclusion, this study has shown that imaging the retinal and choroidal blood flow with OCTA allows for a comprehensive assessment of the CNV net morphology that far exceeds the information brought on by FA, ICGA and SD-OCT. The morphological changes that the CNV net undergoes in response to anti-VEGF are not visible $1 \mathrm{~h}$ after the injection but can be clearly depicted 1 week after treatment. However, despite an initial positive response, new vessel regrowth occurs from $t 2$ to $t 3$. Thus, the freedom and safety of frequent examinations with OCTA appear to provide a method of gauging treatment effects. Future implications of this may very well be the possibility of tailoring treatment regimens on an individual basis, hinging on the CNV net morphology at baseline and its response to a certain anti-VEGF compound.

\section{Disclosure Statement}

R. Silva is an advisory board member for Alcon, Alimera, Allergan, Bayer, Novartis and Théa. J. Figueira is an advisory board member for Alcon, Alimera, Allergan, Bayer, Novartis and Kemin. The other authors have nothing to disclose. 


\section{References}

1 Cachulo M da L, Lobo C, Figueira J, Ribeiro L, Lains I, Vieira A, Nunes S, Costa M, Simao $\mathrm{S}$, Rodrigues V, et al: Prevalence of age-related macular degeneration in Portugal: the Coimbra Eye Study - report 1. Ophthalmologica 2015;233:119-127.

2 Tomany SC, Wang JJ, Van Leeuwen R, Klein R, Mitchell P, Vingerling JR, Klein BE, Smith W, De Jong PT: Risk factors for incident agerelated macular degeneration: pooled findings from 3 continents. Ophthalmology 2004; 111:1280-1287.

3 Sulzbacher F, Kiss C, Munk M, Deak G, Sacu S, Schmidt-Erfurth U: Diagnostic evaluation of type 2 (classic) choroidal neovascularization: optical coherence tomography, indocyanine green angiography, and fluorescein angiography. Am J Ophthalmol 2011;152:799806.

4 Spaide RF: Optical coherence tomography angiography signs of vascular abnormalization with antiangiogenic therapy for choroidal neovascularization. Am J Ophthalmol 2015;160:6-16.

5 Su Z, Ye P, Teng Y, Zhang L, Shu X: Adverse reaction in patients with drug allergy history after simultaneous intravenous fundus fluorescein angiography and indocyanine green angiography. J Ocul Pharmacol Ther 2012;28: 410-413.

6 Lipson BK, Yannuzzi LA: Complications of intravenous fluorescein injections. Int Ophthalmol Clin 1989;29:200-205.

7 Huang D, Swanson EA, Lin CP, Schuman JS, Stinson WG, Chang W, Hee MR, Flotte T, Gregory K, Puliafito CA, et al: Optical coherence tomography. Science 1991;254:11781181.

8 Swanson EA, Izatt JA, Hee MR, Huang D, Lin CP, Schuman JS, Puliafito CA, Fujimoto JG: In vivo retinal imaging by optical coherence tomography. Optics Lett 1993;18:1864-1866.

9 De Carlo TE, Bonini Filho MA, Chin AT, Adhi M, Ferrara D, Baumal CR, Witkin AJ, Reichel E, Duker JS, Waheed NK: Spectraldomain optical coherence tomography angiography of choroidal neovascularization. Ophthalmology 2015;122:1228-1238.

10 Moult E, Choi W, Waheed NK, Adhi M, Lee B, Lu CD, Jayaraman V, Potsaid B, Rosenfeld PJ, Duker JS, et al: Ultrahigh-speed sweptsource OCT angiography in exudative AMD. Ophthalmic Surg Lasers Imaging Retina 2014; 45:496-505.
11 Lumbroso B, Huang D, Jia Y, Fujimoto JG, Rispoli M: Clinical Guide to Angio-OCT: Non-Invasive, Dyeless OCT Angiography, ed 1. New Delhi, Jaypee Brothers Medical Publishers, 2015

12 Savastano MC, Lumbroso B, Rispoli M: In vivo characterization of retinal vascularization morphology using optical coherence tomography angiography. Retina 2015;35: 2196-2203.

13 Jia Y, Tan O, Tokayer J, Potsaid B, Wang Y, Liu JJ, Kraus MF, Subhash H, Fujimoto JG, Hornegger J, et al: Split-spectrum amplitudedecorrelation angiography with optical coherence tomography. Optics Express 2012;20: 4710-4725.

14 Tokayer J, Jia Y, Dhalla AH, Huang D: Blood flow velocity quantification using split-spectrum amplitude-decorrelation angiography with optical coherence tomography. Biomed Optics Express 2013;4:1909-1924.

15 Puliafito CA: OCT angiography: the next era of OCT technology emerges. Ophthalmic Surg Lasers Imaging Retina 2014;45:360.

16 Jia Y, Bailey ST, Wilson DJ, Tan O, Klein ML, Flaxel CJ, Potsaid B, Liu JJ, Lu CD, Kraus MF, et al: Quantitative optical coherence tomography angiography of choroidal neovascularization in age-related macular degeneration. Ophthalmology 2014;121:1435-1444.

17 Kuehlewein L, Sadda SR, Sarraf D: OCT angiography and sequential quantitative analysis of type 2 neovascularization after ranibizumab therapy. Eye 2015;29:932-935.

18 Coscas GJ, Lupidi M, Coscas F, Cagini C, Souied EH: Optical coherence tomography angiography versus traditional multimodal imaging in assessing the activity of exudative age-related macular degeneration: a new diagnostic challenge. Retina 2015;35:22192228.

19 Lumbroso B, Rispoli M, Savastano MC: Longitudinal optical coherence tomography-angiography study of type 2 naive choroidal neovascularization early response after treatment. Retina 2015;35:2242-2251.

20 Huang D, Jia Y, Rispoli M, Tan O, Lumbroso B: Optical coherence tomography angiography of time course of choroidal neovascularization in response to anti-angiogenic treatment. Retina 2015;35:2260-2264.
21 Kuehlewein L, Bansal M, Lenis TL, Iafe NA, Sadda SR, Bonini Filho MA, De Carlo TE, Waheed NK, Duker JS, Sarraf D: Optical coherence tomography angiography of type 1 neovascularization in age-related macular degeneration. Am J Ophthalmol 2015;160:739748.

22 Spaide RF, Klancnik JM Jr, Cooney MJ: Retinal vascular layers imaged by fluorescein angiography and optical coherence tomography angiography. JAMA Ophthalmol 2015;133: 45-50.

23 Coscas G, Lupidi M, Coscas F, Francais C, Cagini C, Souied EH: Optical coherence tomography angiography during follow-up: qualitative and quantitative analysis of mixed type I and II choroidal neovascularization after vascular endothelial growth factor trap therapy. Ophthalmic Res 2015;54:57-63.

24 Muakkassa NW, Chin AT, de Carlo T, Klein KA, Baumal CR, Witkin AJ, Duker JS, Waheed NK: Characterizing the effect of antivascular endothelial growth factor therapy on treatment-naive choroidal neovascularization using optical coherence tomography angiography. Retina 2015;35:2252-2259.

25 Bellou S, Pentheroudakis G, Murphy C, Fotsis $\mathrm{T}$ : Anti-angiogenesis in cancer therapy: Hercules and hydra. Cancer Lett 2013;338:219228 .

26 Schierling W, Troidl K, Troidl C, SchmitzRixen T, Schaper W, Eitenmuller IK: The role of angiogenic growth factors in arteriogenesis. J Vasc Res 2009;46:365-374.

27 Querques G, Capuano V, Frascio P, Bandello F, Souied EH: Emerging therapeutic options in age-related macular degeneration. Ophthalmic Research 2015;53:194-199.

28 Ishikawa M, Jin D, Sawada Y, Abe S, Yoshitomi T: Future therapies of wet age-related macular degeneration. J Ophthalmol 2015; 2015:138070

29 Muether PS, Hermann MM, Droge K, Kirchhof B, Fauser S: Long-term stability of vascular endothelial growth factor suppression time under ranibizumab treatment in age-related macular degeneration. Am J Ophthalmol 2013;156:989-993.

30 Bakri SJ, Snyder MR, Reid JM, Pulido IS Singh RJ: Pharmacokinetics of intravitreal bevacizumab (Avastin). Ophthalmology 2007;114:855-859.

31 Bakri SJ, Snyder MR, Reid JM, Pulido JS, Ezzat MK, Singh RJ: Pharmacokinetics of intravitreal ranibizumab (Lucentis). Ophthalmology 2007;114:2179-2182. 